\title{
Nursing students' experiences of exposure to pandemic influenza A (H1N1)
}

\author{
Hee Sun Kang ${ }^{1}$, Sun-Mi Chae ${ }^{2}$, Myung Sun Hyun ${ }^{3}$, Savitri Singh-Carlson ${ }^{4}$ \\ 1. Department of Nursing, Chung-Ang University, South Korea. 2. College of Nursing, The Research Institute of Nursing \\ Science, Seoul National University, South Korea. 3. College of Nursing, Ajou University, South Korea. 4. School of Nursing, \\ California State University Long Beach, California, USA
}

Correspondences: Sun-Mi Chae. Address: College of Nursing, the Research Institute of Nursing Science, Seoul National University, South Korea. Telephone: 822-740-8816 (work). E-mail: schae@snu.ac.kr

Received: November 1, 2011

Accepted: November 24, $2011 \quad$ Published: May 1, 2012

DOI : $10.5430 /$ jnep.v2n2p63

URL: http://dx.doi.org/10.5430/jnep.v2n2p63

\begin{abstract}
Background: The purpose of this study was to examine the experiences of nursing students with exposure of influenza A (H1N1).

Methods: A qualitative descriptive study design was used. A total of 24 nursing students participated in six focus groups.

Results: The six themes that emerged from the data are as follows: (1) worrying about becoming infected; (2) protecting oneself and others; (3) relying on the nurses in the school health center; (4) being hurt by others' negative reactions; (5) being ambivalent, and (6) being concerned over the high price.

Conclusion: Nursing students who come in contact with patients in a clinical setting must also be considered as candidates for early vaccination. Healthcare professionals, as well as family and friends, should keep in mind that their verbal or nonverbal expressions can hurt others' feelings at a time when special care and support are needed the most. Stigma could be serious barriers of people's access to health services and preventive behaviors. Therefore, education on stigma reduction associated with pandemic infection is essential to enhance public health preparedness.
\end{abstract}

\section{Key words}

Influenza, Vaccination, Nursing student, Focus group, Pandemic

\section{I ntroduction}

A new strain of influenza A (H1N1) was first noted in March 2009 in Mexico ${ }^{[1]}$ which caused global concern as the virus spread quickly across the world. On April 29, 2009, the World Health Organization (WHO) declared the first human influenza pandemic for the twenty-first century. Following this historic emergence of 2009 pandemic in the United States, the community incidence of influenza-like illness reported in April 2009 was 4.7 per 100 adults with half of these adults seeking medical care for their illness ${ }^{[2]}$. England, on the other hand, reported that as many as $70 \%$ of school-aged children in London had been infected ${ }^{[3]}$; whereas Mainland China reporting 1,772 confirmed cases between May 13 to July 22, $2009^{[4]}$. In Korea, a 51-year-old nun who had returned home from a trip to Mexico was first confirmed with influenza A on May 1, $2009^{[5]}$. Influenza A virus had spread rapidly and dramatically throughout the country. 
Anti-viral drugs such as oseltamivir (brand name Tamiflu@) and zanamivir (brand name Relenza $\odot$ ) were recommended as effective treatment options ${ }^{[6,7]}$. Supplies of the 2009 H1N1 vaccine were limited in many countries. Korea Food and Drug Administration (KFDA) approved domestically developed vaccines for H1N1 influenza and delivered them out across the country on October 27, $2009{ }^{[8]}$ according to a priority list that had been developed owing to the vaccine's limited availability. The initial vaccination targeted healthcare workers and those most vulnerable to the severe effects of the virus such as the elderly and very young ${ }^{[8]}$. By February 3, 2010, the outbreak had reached its peak, and subsequently it gradually subsided ${ }^{[9]}$. Once demand among all high-priority groups was met, vaccinations were extended to college students on February 25, 2010.

Unlike many seasonal influenza viruses, the 2009 pandemic of influenza A disproportionately affected the younger population ${ }^{[10]}$ and resulted in widespread outbreaks on college campuses. Owing to the scarcity of vaccines and anti-viral medication, people with influenza-like illnesses had to be tested first in order to obtain a prescription for anti-viral drugs. Many had to suffer long, agonizing, and uncomfortable waits in quarantine, outside their hospital's emergency ward as their laboratory tests were being processed.

Previous studies explored knowledge or perceptions and behaviors of college students regarding the influenza A and the vaccine $^{[11,12]}$. However, there is a lack of knowledge on the experience of college students with confirmed or suspected with influenza A (H1N1) infection during the pandemic period. Additionally the experience of the students studying nursing, medicine, or other health-related majors who need to do clinical practicum in a hospital during the pandemic period has little been explored. Gaining insight is essential for future pandemic planning by elucidating these students' experiences. Therefore, we examined the experience of nursing students who were exposed to the H1N1 strain of influenza A during the pandemic 2009.

\section{Subjects and methods}

\subsection{Study design}

A qualitative descriptive study was conducted, using focus groups interviews ${ }^{[13]}$.

\subsection{Subjects}

A total of 24 nursing students were recruited from two universities located in the Seoul metropolitan area and Kyungki province. Participants were recruited by employing snow-ball sampling and class advertisements. Inclusion criteria were nursing students who were enrolled in the universities and had or were suspected of having influenza A.

\subsection{Data collection}

Data were collected after obtaining written informed consents from the participants. Participants were assured of anonymity and confidentiality. Focus groups were held from October to December, 2009 in seminar rooms at the university, where refreshments were served. Data collection and analysis were conducted concurrently through an interactive process until data saturation had been achieved and themes were identified. Focus groups included four to six participants, and discussions lasted between one to two hours. All participants were encouraged to share and elaborate upon their experiences by the researcher. Regardless of the history of H1N1 exposure, the participants were involved in a group depending on their availability.

\subsection{Statistical analysis}

Each focus group session was audio-taped with the participants' permission and transcribed verbatim. The data from the interviews were analyzed using qualitative content analysis ${ }^{[13]}$. Both primary and secondary researchers coded 
independently and then compared the individual coding in order to establish inter-coder reliability. Coding discrepancies were discussed and resolved by consensus.

\subsection{Rigor}

Trustworthiness was achieved by establishing credibility, dependability, and transferability, according to Lincoln and Guba ${ }^{[14]}$. The credibility of the study was achieved with peer debriefing, and dependability was achieved by conducting an inquiry audit. One investigator, who was not involved in the analysis process, confirmed that the identified themes were supported by the data. The transferability was assured by a rich thick description of the nursing students' experiences.

\section{Results}

A total of 24 nursing students participated in the study. Participants' ages ranged from 19 to 29 years. Four participants were freshmen (16.7\%), eight were sophomores (33.3\%), ten were juniors (41.7\%), and two were seniors (8.3\%). Seventeen were infected with influenza A (H1N1) and took Tamiflu@ or Relenza@. The test results of seven students who were suspected of being infected with H1N1 were negative.

Six major themes were emerged from the focus groups: (1) worrying about becoming infected; (2) protecting oneself and others; (3) relying on the nurses in the school health center; (4) being hurt by others' negative reactions; (5) being ambivalent, and (6) being concerned over the high price.

\section{Worrying about becoming infected}

Participants worried about becoming infected with H1N1 stating that as the H1N1 virus emerged, they only felt concerned about the people that were at risk. However, with the report of the rising numbers of affected people, participants felt that they themselves were also vulnerable to becoming infected with the influenza A virus. Participants expressed their fears as the numbers of those infected with the virus began to rise as follows: "At first, I heard about an infected person only through the TV or news. Now people around me were getting infected. Thus, I felt the circle around me was getting smaller and smaller and tightening me." "Before, only people who were at high risk for H1N1 swine flu died. But [at this time], young and healthy people were also dying from the H1N1 flu. It is a serious situation.”

Students also expressed fear about being exposed to newly confirmed H1N1-positive patients while doing their clinical practicum in a hospital. Occasionally, students had difficulty changing their surgical mask because of shortages of mask supplies. One student stated that, "I am concerned about being improperly protected against the H1N1 virus." And another said, "I am worried about being exposed to swine flu before I can be immunized."

Because nursing students were not considered as healthcare workers, they were not included in the priority group for H1N1 vaccinations. Students expressed their sense of unfairness and insisted that they should have been on the priority list for early vaccination as well since they were in contact with patients. Participants wondered, "What about us? Are we not healthcare professionals?"And, "We should be added to the list of vaccination priority groups, because we are doing our clinical practicum and have a high possibility of being infected or transmitting the virus to the patients."

\section{Protecting oneself and others}

All participants shared that they tried to protect themselves by using preventive measures, such as covering their mouths and noses with tissues when coughing or sneezing, washing their hands frequently, and using hand sanitizer as often as they could, avoiding contact with the sick if possible, and staying home when they themselves were ill.

All participants remained vigilant and watchful against fever or influenza-like symptoms for themselves. One participant stated, "I checked my temperature or any symptoms and tried to recognize for the earliest stage of infection." The most commonly stated reason for remaining vigilant was protection of themselves or others. If they suspected a symptom, they 
sought medical care immediately. However, students who visited the school clinic before going to the hospital thought that going to the hospital with obvious symptoms after stopping by at the school clinic would only increase the chances of cross-infection.

Participants who were ill stayed away from healthy people until they felt healthier. Participants were concerned about their colleagues, families, and communities and sought to prevent cross-infections. Participants infected with H1N1 stayed home in a separate room in an attempt to protect family members, especially elderly members with chronic diseases. Participants attempted to skip classes or clinical practicum if they did not feel well. They stayed home until the H1N1 test confirmed that they themselves had not contracted the infection.

\section{Relying on the nurses in the school health center}

Students who had a fever or flu-like symptoms called or visited school health center or temporary fever management center for students with H1N1 symptoms, where a nurse screened high-risk students and sent them to a designated hospital for confirmation and treatment. Students followed what the nurses directed. Some students said that this was inconvenient because they had to go to the hospital after visiting the school health center, and wanted to have testing and medication dispensed at the school health centre itself.

Although participants took directions from the nurses, the responses of the students who visited their school fever management center varied. Among students who were referred to the hospital and who were then confirmed to have H1N1, some expressed that the nurses' directions were valuable. One said, "It was very helpful that she [the nurse] made me go to the hospital immediately. Otherwise, I wouldn't have gone.” On the other hand, those students whose test results were found to be negative at the hospital expressed criticism about being misdiagnosed at the school health center. One nursing student whose test result was found to be negative stated, "I felt like I went through unnecessary steps." In addition, students responded positively regarding getting a follow-up phone call from the nurse and obtaining a proof-of-absence record for their classes; they felt the nurse had taken good care of them in this situation.

\section{Being hurt by others' negative reactions}

The theme being hurt by others' negative reactions consisted of two subcategories, stigma and blame. Participants who were infected with, or suspected to have H1N1 shared that they noticed a change in others' behavior, and experienced either positive, or negative reactions from friends, family members, and from others.

Stigma: Some participants said they received a text message from friends encouraging them to get well. Others voiced that they felt bad when the nurses tried to avoid contact with them when taking their temperature and when their friends' behaviors were different from their usual behaviors because they may be infected. One of the participants stated, "I stayed away from those with masks, because I felt that those persons wearing masks were probably already infected.”

Blame: Some participants felt condemned and rejected because of these new behaviors by others. When their diagnosis of H1N1 was confirmed, they received calls from their friends who had flu-like symptoms, because they suspected that the participants might have infected them. Participants felt that these friends made them feel guilty and blamed. Regarding this, a participant reported that: "I felt I was grilled for the possibility of infection transmission because she (friend) kept asking where I might have gotten my infection. I felt that she worried only about her.”

Participants felt hurt and alienated when family members and friends treated them as if they were hazardous and overreacted to their illness. They shared that some family members reacted too sensitively to those who had H1N1.

\section{Being ambivalent}

Ambivalence was a dominant theme among the participants; they weighed the pros and cons of taking anti-viral drugs or getting immunized. Participants said they faced competing needs, such as concern over the side effects of the medication or vaccine and wanting to have them anyway, realizing that they offered the promise of protection. We found substantial 
variation in the prevalence of general safety concerns. A small proportion of the participants did not think that they would 'personally benefit' from the medication or vaccine. In contrast, the majority agreed that Tamiflu@, or a vaccine, was the only reliable solution. Several participants expressed concern that Tamiflu@ or the H1N1 vaccine may weaken their immune system and/or may actually cause influenza. Some participants said they were afraid to take Tamiflu@ without confirming whether they had H1N1 because they had heard that once they developed a tolerance to that drug, there would be no medication available if they actually contracted the disease later. On the other hand, those who perceived Tamiflu( or the vaccine as normal and necessary expressed surprise that some people were opposed to the idea of having the drug, saying that it was "better not to regret later, in case something happens."

\section{Being concerned over the high price}

Most participants reported a financial burden as a result of the expense of H1N1 testing. Participants stated that cost was a significant obstacle in recommending that friends get tested to confirm whether or not they were infected. One participant, who did not have much prior information regarding the cost of treatment, reported, "I had to call my parents to send me some money because I didn't know it would cost that much.” Some participants were upset and said, "Testing and receiving treatment is not only for me, it is also to protect other people and the community. Thus, it should be covered and free."

Limited access: The major barrier in being vaccinated was the unavailability of the vaccine. Participants who were doing their clinical practicum seemed especially concerned that they would not have access to the vaccination for themselves until much later. One student expressed this concern by saying, "Even if the vaccine is free, we will not get it until next year.”

\section{Discussion}

This study explored the experience of nursing students' exposure to influenza A H1N1during the 2009 pandemic. Participants were not only worried about getting infected from others but also about transmitting influenza A to others. Participants tried to protect themselves, as well as others, by using preventive measures, such as washing hands frequently or staying home when they were infected. Non-pharmaceutical interventions, such as hand hygiene and use of facemasks were recommended to prevent transmission of influenza. Most of the university students in Turkey (343/402, 85.3\%) adopted at least one preventive measure, and a vast majority believed that hand washing, facemasks, and quarantine were the most effective measures for prevention ${ }^{[15]}$. Korean college students increased their hand hygiene practices during the pandemic ${ }^{[12]}$ similar to this study. During an influenza pandemic, substantial transmission of the virus occurs in households. Oseltamivir ${ }^{[16]}$, hand hygiene, and use of facemasks were effective in preventing household transmission of pandemic influenza ${ }^{[17]}$. Meanwhile some participants in this study believed that people with masks were infected and tried to stay away from them. Wearing a facemask in public during a pandemic might have contributed a negative impression to the others. Public fear and stigma could discourage people to access to health services and preventive behaviors for pandemic infection. Therefore, public education should be delivered on the benefits of preventive health behaviors including wearing a facemask for prevention of the influenza transmission since facemasks could be effective when the perception of influenza risk is high and they are socially acceptable ${ }^{[18]}$.

Participants showed ambivalence about taking anti-viral drugs or getting the influenza A vaccine, which indicates that information regarding the anti-viral drugs and vaccines' safety was not disseminated effectively to the public. The safety of oseltamivir has been well established ${ }^{[19]}$; as the research shows that household members, who had received oseltamivir prophylaxis, were less likely to acquire a secondary infection than those who had not ${ }^{[20]}$. Studies report that the influenza A vaccine proved to be safe and effective against the confirmed H1N1 virus infection ${ }^{[21,22]}$; however, only $9.6 \%$ of college students in Turkey received the pandemic flu vaccine ${ }^{[11]}$. The vast majority $(92.8 \%$; 373/402) of university students indicated that they would not be vaccinated due to concerns of safety of the vaccine and its side effects ${ }^{[15]}$. On the other hand, the rate of influenza A vaccination was higher among students who believed the H1N1 virus was a significant public 
health threat and those who had greater knowledge regarding swine flu and the vaccine ${ }^{[11]}$. Furthermore, those who had gotten seasonal influenza vaccinations over the previous three years were more willing to get the pandemic vaccine ${ }^{[23]}$. Therefore, public health education must focus on the benefits of the influenza vaccine and the importance of vaccination during influenza season. The online, real-time surveillance tool was effective in monitoring influenza activity on campus, providing timely health advice, and decreasing unnecessary visits to the campus medical clinic ${ }^{[24]}$. College students considered electronic communication, such as e-mail, to be the most appropriate way that the university had for communicating health issues ${ }^{[25]}$; thus, using e-mail to educate college students regarding health issues could effectively disseminate correct information to them during a pandemic.

Participants who visited a temporary fever management center in school complained they had to visit the designated hospital clinic when they suspected that they were infected with H1N1, in contrast to many universities in the United States that held school-based vaccination clinics for students ${ }^{[26]}$. Preparedness efforts in universities must include enhancing students' accessibility.

Participants expressed that being tested for influenza A created a financial burden. Although the policy has since changed, owing to a shortage of anti-viral drugs, the government had mandated that they be prescribed only to those infected with influenza A. As a result, students had to pay for the testing fee, which was not covered, or only partially covered; by medical insurance. Taking anti-viral medication benefits not only those taking the drugs but also the public; therefore, in the future, the government should offer diagnostic testing during pandemic infection at no cost, in order to encourage the public to take medication in order to reduce further transmission.

Participants had to stay away from the classes or clinical practicum when they were suspected or confirmed with the pandemic influenza. Thus, it is vital to make an arrangement for students who missed the classes to catch up the class sessions using an alternative learning method, such as online teaching resources. Faculty unfamiliar with technology could be assisted in developing their ability to provide online resources to their quarantined students ${ }^{[23]}$. Cessation of nursing class, clinical practicum, or patient contact during an epidemic or pandemic is potentially disruptive to nursing education. During the SARS epidemic, the use of web-based learning, role playing, video vignettes, and practicing with medical mannequins and actual patients minimized disruptions to medical education in Singapore ${ }^{[27]}$. Strategies that allow clinical teaching to continue without exposing nursing students to infected or potentially infected patients might be required. Therefore, rather than exposing students to high-risk patients during clinical practicum, using patient simulators or standardized patients in the lab could be alternative teaching methods.

Potential healthcare workers, such as nursing students, especially those who have patient contact in a clinical setting, should be considered as a first priority for vaccination. In addition, nursing schools should adopt policies on student vaccinations and should encourage annual influenza vaccinations by offering them at no cost ${ }^{[28]}$. Improvements are required in covering the costs and services for influenza vaccinations and this would benefit students. Furthermore, most participants reported negative experiences related to virus exposure. Healthcare workers, as well as family and friends, should keep in mind that their verbal or nonverbal expressions could hurt the feelings of infected persons, when special care and support are needed the most at this fearful time.

\section{Conclusion}

In conclusion, misconceptions about the anti-viral drugs and vaccine were common. Efforts must be made to convince nursing students that the benefits outweigh the actual and potential risks of anti-viral drugs or vaccinations. Nursing students and their family and friends should be provided with information on the prevention and treatment of the infection to lower the level of anxiety and to prevent cross-infection. This can be done using various materials, such as written, audiovisual, and web-based information. 
Our study suggests that nursing students who are doing their clinical practicum must be included in the first-priority vaccination list. Additional services, such as testing for $\mathrm{H} 1 \mathrm{~N} 1$ and receiving anti-viral drugs, should also be provided from the school health centers for the convenience of their students and minimizing cross-infection on campus and in the community. This study is limited as it only included undergraduate nursing students; therefore including parents of the students infected with H1N1 would be beneficial for future studies as well as faculty members perception.

\section{References}

[1] Michaelis M, Doerr HW, Cinatl JJr. Novel swine-origin influenza A virus in humans: another pandemic knocking at the door. Med Microbiol Immunol. 2009; 198(3):175-183. PMid:19543913 http://dx.doi.org/10.1007/s00430-009-0118-5

[2] Reed C, Angulo FJ, Biggerstaff M, Swerdlow D, Finelli L. Influenza-like illness in the community during the emergence of 2009 pandemic influenza A(H1N1)-survey of 10 states, April 2009. Clin Infect Dis. 2011; 52(Suppl 1): S90-S93. PMid:21342906 http://dx.doi.org/10.1093/cid/ciq024

[3] Hardelid P, Andrews NJ, Hoschler K, et al. Assessment of baseline age-specific antibody prevalence and incidence of infection to novel influenza A/H1N1 2009. Health Technol Assess. 2010; 14 (55):115-192. PMid:21208549

[4] Ding F, Zarlenga DS, Qin C, Ren X. A novel algorithm to define infection tendencies in H1N1 cases in Mainland China. Infect Genet Evol. 2011; 11(1):222-226. PMid:20951840 http://dx.doi.org/10.1016/j.meegid.2010.09.015

[5] Lee DH, Shin SS, Jun BY, Lee JK. National level response to pandemic (H1N1) 2009. J Prev Med Public Health. 2010; 43(2):99104. PMid:20383041 http://dx.doi.org/10.3961/jpmph.2010.43.2.99

[6] Agrawal R, Rewatkar PV, Kokil GR, Verma A, Kalra A. Oseltamivir: a first line defense against swine flu. Med Chem. 2010; 6(4): 247-251. PMid:20843284

[7] Dotis J, Roilides E. H1N1 Influenza A infection. Hippokratia. 2009; 13(3):135-138. PMid:19918299

[8] Kwon Y, Cho HY, Lee YK, Bae GR, Lee SG. Relationship between intention of novel influenza A (H1N1) vaccination and vaccination coverage rate. Vaccine. 2010; 29(2):161-165. PMid:21055495 http://dx.doi.org/10.1016/j.vaccine.2010.10.063

[9] Kim JH, Yoo HS, Lee JS, et al. The spread of pandemic H1N1 2009 by age and region and the comparison among monitoring tools. J Korean Med Sci. 2010; 25(7):1109-1112. PMid:20592911 http://dx.doi.org/10.3346/jkms.2010.25.7.1109

[10] Jagannatha Rao SR, Rao MJ, Swamy N, Umapathy BL. Profile of H1N1 infection in a tertiary care centre. Indian J Pathol Microbiol. 2011; 54(2):323-325. PMid:21623082 http://dx.doi.org/10.4103/0377-4929.81618

[11] Ozer A, Kirecci E, Ekerbicer HC, Celik M. Medical faculty and school of health student knowledge of and behavior regarding swine flu and vaccine, in Kahramanmaras, Turkey. Southeast Asian J Trop Med Public Health. 2011; 42(1):161-167. PMid:21323179

[12] Park JH, Cheong HK, Son DY, Kim SU, Ha CM. Perceptions and behaviors related to hand hygiene for the prevention of H1N1 influenza transmission among Korean university students during the peak pandemic period. BMC Infect Dis. 2010; 10:222. PMid:2066322 http://dx.doi.org/10.1186/1471-2334-10-222

[13] Krueger R, Casey M. Focus Groups - A Practical Guide for Applied Research. 3rd ed. Thousand Oaks, CA: Sage; 2000.

[14] Lincoln YS, Guba EG. Naturalistic Inquiry. Beverly Hills, CA: Sage. 1985.

[15] Akan H, Gurol Y, Izbirak G, et al. Knowledge and attitudes of university students toward pandemic influenza: a cross-sectional study from Turkey. BMC Public Health. 2010; 10:413. PMid:20626872 http://dx.doi.org/10.1186/1471-2458-10-413

[16] Carcione D, Giele CM, Goggin LS, et al. Secondary attack rate of pandemic influenza A(H1N1) 2009 in Western Australian households, 29 May-7 August 2009. Euro Surveill. 2011; 16(3): pii: 19765.

[17] Cowling BJ, Chan KH, Fang VJ, et al. Facemasks and hand hygiene to prevent influenza transmission in households: a cluster randomized trial. Ann Intern Med. 2009; 151(7): 437-446. PMid:19652172

[18] Ferng YH, Wong-McLoughlin J, Barrett A,Currie L, Larson E. Barriers to mask wearing for influenza-like illnesses among urban Hispanic households. Public Health Nurs. 2011;28(1):13-23. Van, D., McLaws, M. L., Crimmins, J., MacIntyre, C. R., \& Seale, H. (2010). University life and pandemic influenza: attitudes and intended behaviour of staff and students towards pandemic (H1N 1) 2009. BMC Public Health, 10:130. PMid:20226093 http://dx.doi.org/10.1186/1471-2458-10-130

[19] Donner B, Bader-Weder S, Schwarz R, Peng MM, Smith JR, Niranjan V. Safety profile of oseltamivir during the 2009 influenzapandemic. Pharmacoepidemio Drug Safe. 2011; 20(5):532-543. PMid:21448900 http://dx.doi.org/10.1002/pds.2136

[20] Leung YH, Li MP, Chuang SK. A school outbreak of pandemic (H1N1) 2009 infection: assessment of secondary household transmission and the protective role of oseltamivir. Epidemiol Infect. 2011; 139(1):41-44. PMid:20561390 http://dx.doi.org/10.1017/S0950268810001445 
[21] Song JY, Cheong HJ, Heo JY, et al. Effectiveness of the pandemic influenza A/H1N1 2009 monovalent vaccine in Korea. Vaccine. 2011; 29(7):1395-1398. PMid:21199701 http://dx.doi.org/10.1016/j.vaccine.2010.12.050

[22] Wu J, Xu F, Lu L, et al. Safety and effectiveness of a 2009 H1N1 vaccine in Beijing. N Engl J Med. 2010; 363(25):2416-2423. PMid:21158658 http://dx.doi.org/10.1056/NEJMoa1006736

[23] Van D, McLaws ML, Crimmins J, MacIntyre CR, Seale H. University life and pandemic influenza: attitudes and intended behaviour of staff and students towards pandemic (H1N1) 2009. BMC Public Health. 2010; 10:130. PMid:20226093 http://dx.doi.org/10.1186/1471-2458-10-130

[24] Jaeger V, Shick-Porter M, Moore D, Grant D, Wolfe V. GotFlu channel: an online syndromic surveillance tool supporting college health practice and public health work. J Am Coll Health. 2011; 59(5):415-418. PMid:21500061 http://dx.doi.org/10.1080/07448481.2010.521961

[25] Seale H, McLaws ML, Van D, Crimmins J, Macintyre CR. University communication strategies during a pandemic-were the messages received? J Public Health Manag Pract. 2011; 17(1):E29-32. PMid:21135652

[26] Sunil TS, Zottarelli LK. Student utilization of a university 2009 H1N1 vaccination clinic. Vaccine. 2011; 29:4687-4689. PMid:21601605 http://dx.doi.org/10.1016/j.vaccine.2011.04.110

[27] Lim EC, Oh VM, Koh DR, Seet RC. The challenges of "continuing medical education" in a pandemic era. Ann Acad Med Singapore. 2009; 38(8):724-726. PMid:19736579

[28] Lindley MC, Lorick SA, Spinner JR, et al. Student vaccination requirements of U.S. health professional schools: a survey. Ann Intern Med. 2011; 154(6):391-400. PMid:21403075 